\title{
MIGRAÇÃO E METAMORFOSE DE UM MITO BRASILEIRO: O SACI, TRICKSTER DA CULTURA CAIPIRA
}

Renato da Silua Queiroz*

\begin{abstract}
RESUMO: O artigo analisa, de uma perspectiva antropológica, a figura mítica do Saci, entidade fantástica originária do mundo rural paulista, manipulada e convertida pela midia em símbolo da nacionalidade.
\end{abstract} nacionais.

UNITERMOS: Minorias; preconceito racial; mitos brasileiros; trickster; simbolos

Este artigo trata da figura mítica do Saci (também conhecido como Sacipererê), entidade fantástica brasileira convertida em símbolo nacional, cuja trajetória tem início nas áreas rurais paulistas do século XVIII e se prolonga pelo contexto urbano de todo o país até a atualidade ${ }^{1}$.

Figurado habitualmente como um molecote preto, de uma só perna, capuz vermelho à cabeça e cachimbo à boca, o Saci é o senhor das artimanhas, das travessuras e dos redemoinhos do vento, exibindo traços típicos do trickster, personagem ambíguo e contraditório com o qual os antropólogos já se habituaram a conviver ${ }^{2}$. Nos relatos antigos o Saci aparece como uma das mais curiosas e contraditónas figuras entre as que integram o elenco dos seres fabulosos tradicionalmente conhecidos através de todo o mundo rural de influência paulista. Colocado ao lado de outras criaturas fantásticas, lúgubres $e$ ameaçadoras - Lobisomem, Canhambora, Mula-sem-cabeça, Corpo-seco etc. -, o Saci se destaca como um tipo singular, protagonista de aventuras em que predominam a astúcia, a zombaria e a malicia.

- Professor do Depto. de Antropologia da FFLCH/USP.

1. Informaçōes detalhadas a respeito do Saci e das interpretaçōes aqui apresentadas encontram-se em QUEJROZ,Renato da Silva. O Herói-trapaceiro: reflexōes sobre a figura do trickster. Tempo Social, Revista de Sociología da USP. São Paulo, v. 3, n. 1-2, p. 93-107, 1991.

2. ldem, ibidem. Sobre a figura do trickster. 
Enquanto as demais criaturas, ao que parece, vão pouco a pouco se extingüindo, no mesmo ritmo de dissoluçāo dos grupos campesinos mais autárquicos, o Saci, astucioso, insiste em permanecer vivo. Ele migrou, mas sem se estabelecer, como a maioria dos migrantes rurais, na periferia das grandes cidades, pois se fixou em seus redutos mais valorizados.

$\mathrm{Na}$ cidade de São Paulo registrei a existência de um cinema, uma escola infantil e um ônibus urbano que levam o seu nome. Há também um pichador de paredes que se especializou em fixar imagens do moleque sempre a urinar, com ar de deboche, em diversos locais públicos. Já encontrei reproduçōes do perneta confeccionadas em plástico, cerâmica, feltro e madeira, algumas das quais me foram ofertadas por amigos. As bancas de jornais anunciam o novo número da revista em quadrinhos $A$ Turma do Pererê le o personagem central, o Saci, é definido como "o mais brasileiro de todos os heróis"), enquanto o seriado da TV, O Sítio do Picapau Amarelo, divulga sua imagem marota através de todo o país. Artistas de teatro recebiam o prêmio "Saci", instituído pelo jornal O Estado de S.Paulo para distingüir aqueles que representam, "que fazem arte". Além disso, cartazes publicitários de uma instituiçāo financeira trazem a sua figura estampada em destaque, e um curso de inglês para crianças tem como anunciante o próprio perneta - "aprenda inglês brincando", diz um destes folhetos.

Certa ocasião, identifiquei o moleque travesso no interior de uma igreja, convivendo sem constrangimentos com santos e anjos barrocos ${ }^{3}$. O artista responsável pela decoração do templo. afirmou que o seu propósito fora o de "dar um toque de brasilidade" nas pinturas. Para tanto, prosseguiu, nada melhor do que introduzir o pequeno demônio na companhia dos santos católicos.

Como entender esta trajetória, da condiçāo inicial de objeto de crença à apropriaçāo e estilização pela literatura de ficção e pela midia, até, chegar, finalmente, ao status de símbolo da nacionalidade? Afinal, trata-se de um personagem cuja origem rural não o impediu de se fixar, como herói, nas áreas urbanizadas. Como explicar, ainda, que uma sociedade tão profundamente marcada pelo preconceito racial, pelo proclamado apego aos princípios cristãos e pelo desprezo com que trata a população pobre do campo possa acolher com tanta simpatia a figura de um diabrete preto, perneta e migrante rural?

Segundo Câmara Cascudo 4 , o Saci-moleque, notivago e arredio, surge apenas ao final do século XVIII, nas áreas meridionais brasileiras. Observa ainda que o mito teria se originado no Paraguai, com a dispersão dos Tupi-Guarani, esclarecendo que camponeses paraguaios informam sobre os Yaci-Yateré, duen-

3. Igreja de São Benedito, na cidade de Serra Negra, Estado de São Paulo, cujas pinturas sāo de autoria de Cid Serra Negra.

4. CASCUDO, Luis da Cămara. Geografia dos mitos brasileiros. Rio de Janeiro, José Olympio, 1947. p. 58. (Documentos Brasileiros, 52). 
des vermelhos, do tamanho aproximado ao de uma criança de sete anos, que costumam roubar fogo dos acampamentos, pois não sabem fazê-lo.

Concepção bem diversa é aquela formulada por Souza Carneiro ${ }^{5}$, para quem o Saci seria, em essência, a versão brasileira de um mito africano, o "Dudu-Calunga", meninote preto, perneta e zarolho. Por outro lado, Gustavo Barroso $0^{6}$ nos garante que, a nāo ser pela cor, o Saci assemelha-se aos "Sciapodos", entes fabulosos descritos por Plinio no clássico História Natural.

Lindolfo Gomes, por sua vez, observa que o mito do Saci é ameríndio na origem, modificado posteriormente pelo colonizador europeu e pelo elemento africano. Trata-se, segundo este autor, da conhecida lenda indígena do casal de irmãos incestuosos. A irmã, temendo ser descoberta, subiu ao céu por um caminho de flechas lançadas ao ar, transformando-se na Lua (Jaci), enquanto o irmão se transforma numa ave, o mutum. Assim, Saci-pererê seria forma deturpada de Jaci-Taperê (Tapera da Lua), lugar maldito e assombrado onde mensalmente aparece a índia incestuosa em forma de $\mathrm{Lua}^{7}$.

Como se vê, os autores encontram neste mito elementos que thes permitem apontar diferentes origens ou influências incorporadas na composição do duende fantástico. Consciente de que o mito constitui um verdadeiro amálgama de influências indígenas, africanas e portuguesas, Amadeu Amaral ${ }^{8}$, por exemplo, considera que "o Saci marca um momento importante, uma encruzilhada da nossa [brasileira] viagem histórica. O Saci é talvez um símbolo", conclusão a que chega também outro folclorista, Alceu Maynard Araújo, para quem o Saci representa o "mito sintese" das "três raças" geradoras da "alma nacional".

Temos aqui uma mudança de enfoque: a ênfase, que antes incidia sobre a busca de contribuições étnicas particulares presentes na configuração do mito, começa a ceder terreno a um outro tipo de reflexāo, ou seja, àquela que procura encontrar a sua especificidade, definindo-o como produto da fusão de contribuiçōes diferentes que dão origem a uma nova síntese, "expressão da alma nacional". Esses autores se esquecem, contudo, que, no Brasil, indios, brancos e negros jamais puderam conviver em igualdade de condições, e que também não partilharam seus respectivos patrimônios culturais de maneira desinteressada $e$ generosa. Seria mais prudente esperar que as narrativas que tratam do Saci expressassem muitos dos problemas, das contradiçōes e das ambigüidades exis-

5. SOUZA CARNEIRO. Os mitos africanos no Brasil: ciência do folk-lore. Sảo Paulo, Nacional, 1937. p. 253. (Brasiliana, 103).

6. BARROSO, Gustavo. O sertāo e o mundo. Rio de Janeiro, Leite Ribeiro, 1923. p. 262-3.

7. GOMES, Lindolfo. Contos populares brasileiros. 3. ed. Sāo Paulo, Melhoramentos, 1965. p. 92-4. (Panorama da Literatura Brasileira).

8. AMARAL, Amadeu. Tradiçōes populares. São Paulo, Inst. Progresso Editorial, 1948. p. 44.

9. ARAÚJO, Alceu Maynard. Folclore Nacional. v. I: Festas, bailados, mitos e lendas. São Paulo, Melhoramentos, 1964. p. 416. 
tentes no seio de uma sociedade hierarquizada, multirracial, com um longo passado escravista e profundamente desigual como a brasileira.

Considerando a desigualdade inerente às posiçōes estruturais ocupadas nesta sociedade pelos seus diferentes segmentos étnicos, Florestan Fernandes nos oferece um seguro passo para a compreensão do mito em questão. Segundo este autor, o Saci seria, em grande medida, o produto da "africanizaçāo" de um duende ameríndio. Tal processo de "africanizaçāo" nos faria observar as consequiências advindas "da reação do negro sobre os elementos dos folclores ibéricos $e$ indigenas e mostram que, relativamente ao folclore do branco, há uma transferência das piores situações para o negro, que passa para um plano que poderíamos considerar inferior" 10 .

Como já foi indicado, o Saci-moleque surge nas áreas de expansāo geográfica dos paulistas por volta do final do século XVIII, período em que a estrutura social nos sertōes da "Paulistânia", até então pouco diferenciada, se vê alterada com a ampliação dos latifúndios $e$ a introdução de māo-de-obra escrava de origem africana. Povoada desde os primórdios do periodo colonial por uma população esparsa e seminômade, de origem indígena e portuguesa, a multiplicação das fazendas nestas áreas, onde "as camadas superiores puderam afazendar-se graças à cana-de-açúcar e ao braço negro" configura "os traços fundamentais da cultura caipira, que se vinha esboçando desde o início da colonizaçāo"11.

Relativamente a esta nova ordem de coisas, o caipira típico, segmento da população livre e pobre daquelas regiōes, revelou, segundo Antonio Candido, dificuldade de "adaptação rápida às formas mais produtivas e exaustivas de trabalho, no latifúndio da cana e do café". Este tipo, "senhor do seu destino graças à independência precária da miséria, refugou o enquadramento do salário e do patrāo, como eles lhe foram apresentados, em moldes traçados para o trabalho servil. O escravo e o colono europeu foram chamados, sucessivamente, a desempenhar o papel que ele [o caipira] não pôde, não soube ou não quis encarnar"12.

Desta forma, nas áreas indicadas acima, as referidas transformaçōes produzem e colocam em confronto, simultaneamente, a nova camada dominante, uma populaçāo campesina formada pelos homens livres e pobres do campo e o segmento negro cativo. $\dot{E}$ este o tenso contexto em que emerge a figura do Sacimoleque.

De acordo com as figurações procedentes desta "elite" rural, o Sacimoleque é sempre preto. A análise cuidadosa dos relatos compulsados nos revela

10. FERNANDES, Florestan. Mudanças sociais no Brasil: aspectos do desenuolvimento da sociedade brasilelra. Săo Paulo, Difel, 1960. p. 345-8. (Como e Alma do Brasil).

11. ANTONIO CANDIDO. Os Parceiros do Rio Bonito: estudo sobre o caipira paulista e a transformação dos seus meios de vida. Rio de Janeiro, José Olympio, 1964. p. 63.

12. Idem, ibidem. p. 60 . 
que a sua caracterização "física" é construída mediante o emprego de elementos cristalizados nas representações coletivas, deformadas e preconceituosas, definidoras do negro brasileiro como um ser inferior, próximo à animalidade, portador de atributos maléficos. Mesmo quando essas formulações são mais jocosas, destacando o caráter trickster do nosso personagem, dando-nos a impressão de atenuar ou eliminar as conotaçōes pejorativas, elas acabam por reforçar, na verdade, esse propósito de desqualificar o individuo discriminado, embora possam dissimular a existência do preconceito.

Para esta camada dominante rural, os traços fisionômicos do Saci são semelhantes aos de um macaco, bode, morcego ou corvo - animais que se prestam às comparações $e$ às ofensas dirigidas ao negro. Mal-cheiroso, hematófago, demoníaco, ladrāo, claudicante e feiticeiro, seus hábitos noturnos correspondem aos das aves agourentas que circulam à noite. Ademais, o Saci pode ser escravizado (como todos os negros), e suas manifestaçōes no interior das moradias limitam-se ao cômodo mais desqualificado, lugar dos subalternos e das negras domésticas: a cozinha. Segundo tais relatos, o Saci não passaria de uma "crendice", manifestação da mentalidade atrasada e supersticiosa atribuída aos campesinos $e$ aos pretos feiticeiros.

Para os camponeses-caipiras, entretanto, o Saci-moleque também é preto, mas não exala cheiro de enxofre nem exibe parentesco com o demônio. Segundo essas representaçōes, as manifestaçöes do nosso trickster (dançarino, pregador de peças, fazedor de cócegas, assiduo freqüentador das fronteiras, entidade que se manifesta através de assovios sarcásticos) denotam uma inequívoca vocação contestadora, a zombaria e o deboche constituindo as suas armas prediletas: nos caminhos mais desertos, o Saci assusta os cavaleiros, derrubando-os da montaria, afastando-se a seguir ao som de assovios e gargathadas. Nos pastos, embaraça fortemente as crinas dos cavalos, sugando-lhes também o sangue.

Como é sabido, no contexto em pauta o cavalo foi sempre um simbolo de poder, qualificação social e distinçāo estamental, meio de transporte e de dominação. No Brasil, a plebe rural, gente sem terras e sem cavalos, sempre andou a pé e descalça, em lombo de burro ou de boi. Não parece ser à toa, portanto, que o alvo predileto das travessuras do Saci, nos relatos dos campesinos, seja justamente o cavaleiro em trânsito pelo sertão. A expressão "cair do cavalo" não traduz humilhaçāo, equivoco, rebaixamento de condiçāo?

De seu lado, os negros escravos atribuiam às peraltagens do moleque travesso uma série de ocorrências - pequenos furtos, quebra de utensilios e ferramentas etc - pelas quais, não fosse o Saci, acabariam sendo mais seriamente responsabilizados e punidos. Sabe-se, a propósito, que os senhores temiam a feitiçaria e as divindades dos negros cativos, e que estes faziam uso desse temor como estratégia de sobrevivência. 
Durante o período escravista, o Saci-moleque permaneceu vinculado ao contexto rural constituido com a expansão dos paulistas. As suas façanhas sempre estiveram associadas aos interesses antagônicos que compunham a sociedade agrária da época: senhores, escravos e a população livre, os pobres do campo.

Com a urbanização, a industrialização $e$ a passagem para o trabalho livre, o Saci-moleque transfere-se para os centros urbanos, perdendo muitos dos traços que exibia no contexto de origem. As narrativas de fins do século XIX e início do $\mathrm{XX}$ apresentam ainda um Saci voluntarioso, agressivo, investido de poderes sobre-humanos.

A sua migração para o mundo urbano é devida, em grande parte, ao escritor Monteiro Lobato, autor de importantes obras destinadas ao público infanto-juvenil. Na altura dos anos vinte do presente século (marcado pela industrialização, expansão urbana e decadência da aristocracia rural), Lobato entendia que as tradições mais "autênticas" dos brasileiros estavam sendo substituidas por elementos culturais "alienígenas", atribuindo tal "descaracterizaçāo" sobretudo à incorporaçăo de costumes europeus e norte-americanos e à forte presença de imigrantes italianos, espanhóis e japoneses que se estabeleceram no Brasil para substituir a mão-de-obra escrava de origem africana.

Naquele momento, o campesino surgia nas idealizaçōes dos citadinos como um elemento "puro" e "autêntico", que nāo se deixava afetar pelas "nocivas" influências estrangeiras, "desfiguradoras" das tradições brasileiras. Lobato elege justamente o Saci para representar o que de mais genuinamente brasileiro poderia haver na cultura campesina. O caráter trickster do pregador-de-peças ajustava-se perfeitamente ao tom humorístico das críticas então dirigidas ao modo-devida urbano $e$ aos estrangeiros. Mas era preciso fazer do Saci uma criatura mais cativante, capaz de despertar a simpatia de todos os brasileiros. Era preciso, pois, domesticá-lo.

Com a publicação do livro O Saci, Monteiro Lobato fez do nosso personagem uma figura heróica das histórias infantis. Preservou, contudo, o caráter trickster do menino travesso: o herói apresentava ainda uma origem anormal, alternava boas e más açōes, era simultaneamente astuto e tolo e dispunha de poderes mágicos. Além disso, o escritor não o livrou de todos os traços estigmatizantes, uma vez que o pequeno herói exalava um forte odor de enxofre, temia os símbolos cristãos e não estava imune ao cativeiro. Essas marcas foram apagadas posteriormente e graças à atuaçāo da mídia, que completou a tarefa de "domesticar" o Saci, despojando-o dos poderes mágicos, agressividade e ousadia.

Dessa forma, a figura do moleque rebelde, perturbador e desordeiro, acabou sendo substituída pela imagem bem-comportada do menino sorridente $e$ simpútico, devidamente controlada pelos agentes da cultura de massas. Transformado em símbolo nacional, perdeu os atributos que o mantinham, graças à variedade $e$ intençōes das narrativas, nas fronteiras entre as classes $e$ 
etnias. Passou a habitar estampas de livros, revistas e jornais; animou-se nas telas do cinema e da TV; entrou de parceiro no cotidiano de crianças e adultos, nas ruas e nas residências.

Dentre as entidades sobrenaturais das regiōes desbravadas $e$ povoadas pelos paulistas, Lobato escolheu justamente o Saci para figurar como personagem de destaque em diversas aventuras. Essa escolha não se deu ao acaso, pois o caráter trickster, que já fazia do Saci uma entidade singular, pesou decisivamente nesse sentido. Eliminando-se as características mais rudes do herói, acentuaram-se as diferenças existentes entre ele e as criaturas mais sinistras - Lobisomem, Caipora, Mulasem-cabeça, Canhambora etc. O antropomorfismo do perneta, contrastando com as encarnaçōes zoomórficas da maior parte dos outros seres sobrenaturais, parece ter sido de grande valia na ocasião de sua passagem para o mundo urbano.

Como ele era um ser sobrenatural que expressava a divisão dos brasileiros, nada melhor do que forçá-lo a uni-los, opondo-os aos "estrangeiros". E assim o Saci começou a ficar famoso. Domesticado, o Saci-menino ingressa definitivamente na era da indústria cultural e da publicidade. Com o desenvolvimento do rádio e o advento da televisão o nosso personagem alcança projeção nacional. Despojado dos seus traços mais sarcásticos, agressivos e contestadores, restaramThe as feições miúdas e o ar brincalhão (ao contrário dos duendes europeus, figurados entre nós como velhos e de longas barbas brancas), não se associando mais às situações que colocavam em confronto grupos sociais antagônicos nas regiōes e nos periodos já indicados.

Os mais ingênuos podeniam acreditar que a imagem de um negrinho divertido e buliçoso não traduziria concepções desfavoráveis ao segmento de origem africana da população brasileira. Afinal, converter um personagem negro em símbolo da nacionalidade não traduz exatamente ausência de preconceito? A resposta poderia ser assim formulada: os negros costumam ser representados, sobretudo nos meios de comunicação, através das estereotipadas figuras do bandido, do malandro $e$, sobretudo, do bufăo. A dignidade $e$ a respeitabilidade são em geral atributos exclusivos dos personagens brancos.

Diversos autores já observaram que na sociedade brasileira até mesmo as criações culturais dos grupos subalternos terminam sendo apropriadas, redefinidas $e$ exploradas pelas camadas dominantes. Esse processo sutil consiste em "limpar", "domesticar" tais criaçōes, colocá-las no domínio da "ordem", transformando-as, muitas vezes, em simbolos nacionais. Os exemplos mais conhecidos referem-se ao samba, ao candomblé, à feijoada e aos temas da malandragem ${ }^{13}$.

13. BORGES PEREIRA, João Baptista. Negro e cultura negra no Brasil atual. Revista de Antropologia. São Paulo, v. 26 , 1983.; FRY, Peter. Para inglés ver: Identidade e polftica na cultura brasileira. Rio de Janeiro, Zahar, 1982; OLJVEN, Ruben George. A elaboraçăo dos simbolos nacionais na cultura brasileira. Revista de Antropologia. São Paulo, v. 26, 1983. 
Convertendo manifestaçōes culturais que tiveram origem no interior de grupos subaltemos (etnias ou classes) em símbolos da nacionalidade, os segmentos sociais dominantes reafirmam a concepção de que o Brasil constitui uma realidade exemplar, um "paraíso" intocado das lutas de classes e dos preconceitos.

Em razão disso, os grupos subalternos e discriminados terminam sendo duplamente "desarmados". Em primeiro lugar, porque perdem sistematicamente os recursos por meio dos quais poderiam construir, preservar e expressar uma identidade grupal imprescindivel à afirmação de direitos e à reivindicação de oportunidades junto aos segmentos dominantes. Em segundo, porque a difusão estilizada dessas manifestaçōes dificulta o reconhecimento das diferenças e desigualdades mantidas por uma ordem injusta $e$ intolerante.

Por outro lado, as elites põem simultaneamente em prática uma espécie de autocontrole, procurando não dar demonstrações explícitas das suas avaliações preconceituosas. "Não se fala em corda em casa de enforcado", é a expressão que traduz admiravelmente tal estratégia. Os integrantes dessas elites, por sinal, são os que mais combatem os estudos realizados a respeito da discriminação racial ou das fricçōes de classes, alegando que os pesquisadores é que estariam interessados em desencadear conflitos num pais que desconheceria tais problemas.

Para concluir, restaria assinalar que o processo que leva à domesticação do Saci é obtido mediante uma curiosa "juvenilização" do duende, evocando o fenômeno evolutivo da "neotenia", à semelhança, por exemplo, da domesticação processada na figura de "Mickey Mouse" e muito bem identificada por Jay Gould $^{14}$. De fato, com o passar do tempo o temperamento de ambos os personagens se acalma $e$ as suas feições vão se tomando cada vez mais jovens: redução de estatura, aumento proporcional das dimensōes dos olhos e da cabeça, cujo formato passa a ser arredondado; diminuição no tamanho dos membros, queixo, nariz e dentes ${ }^{15}$. De resto, ambos tomaram-se assim mais cativantes.

\section{MIGRATION AND METAMORPHOSIS OF A BRAZILIAN MYTH : THE SACI A TRICKSTER IN THE POPULAR CULTURE}

ABSTRACT: This article analyses, from an anthropological perspective, the mythical figure "Saci", a creature of fantasy, born from the rural paulista world, manipulated by the media and converted into a national symbol. folklore.

KEYWORDS: Brazilian mythology; trickster; racial prejudice; minority groups;

14. GOULD, S. Jay. Uma homenagem biológica a Mickey Mouse. In: O polegar do panda: reflexōes sobre história natural. Lisboa, Gradiva, s/d. (Ciència Aberta, 12).

15. Sabe-se que os seres humanos sentem afeição pelos traços infantis dos bebès e também dos filhotes de animais, e que isto serve para provocar sentimentos temos e protetores no adulto. Ver OTTA, Ema. $O$ sorriso e seus significados. Petrópolis, Vozes, 1994. 